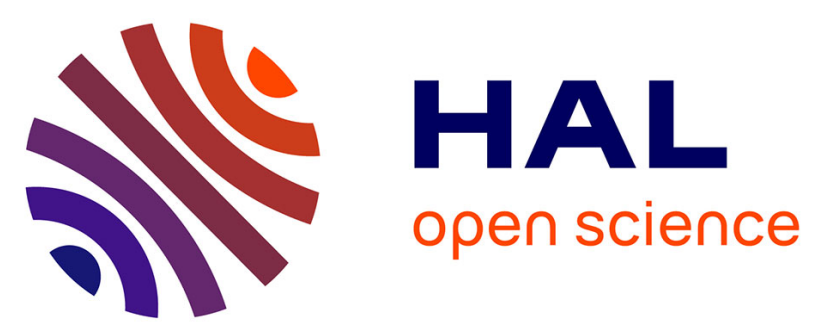

\title{
Shifts and linkages of functional diversity between above- and below-ground compartments along a flooding gradient
}

Corentin Abgrall, Matthieu Chauvat, Estelle Langlois, Mickael Hedde, David Mouillot, Sandrine Salmon, Bruna Winck, Estelle Forey

\section{To cite this version:}

Corentin Abgrall, Matthieu Chauvat, Estelle Langlois, Mickael Hedde, David Mouillot, et al.. Shifts and linkages of functional diversity between above- and below-ground compartments along a flooding gradient. Functional Ecology, 2017, 31 (2), pp.350-360. 10.1111/1365-2435.12718 . hal-01594786

\author{
HAL Id: hal-01594786 \\ https://hal.science/hal-01594786
}

Submitted on 26 Sep 2017

HAL is a multi-disciplinary open access archive for the deposit and dissemination of scientific research documents, whether they are published or not. The documents may come from teaching and research institutions in France or abroad, or from public or private research centers.
L'archive ouverte pluridisciplinaire HAL, est destinée au dépôt et à la diffusion de documents scientifiques de niveau recherche, publiés ou non, émanant des établissements d'enseignement et de recherche français ou étrangers, des laboratoires publics ou privés.

\section{다(1)(2)}

Distributed under a Creative Commons Attribution - ShareAlikel 4.0 International 


\title{
Shifts and linkages of functional diversity between above- and below-ground compartments along a flooding gradient
}

\author{
Corentin Abgrall ${ }^{*, \dagger, 1}$, Matthieu Chauvat ${ }^{\dagger, 1}$, Estelle Langlois ${ }^{1}$, Mickaël Hedde ${ }^{2}$, David Mouillot $^{3}$, \\ Sandrine Salmon ${ }^{4}$, Bruna Winck ${ }^{5}$ and Estelle Forey ${ }^{1}$ \\ ${ }^{1}$ Ecodiv URA/EA 1293, IRSTEA, FR CNRS 3730 SCALE, UFR Sciences et Techniques, Normandie université, \\ Université de Rouen, 76821 Mont Saint Aignan Cedex, France; ${ }^{2}$ INRA, UMR 1402 Ecosys, RD 10, 78026 Versailles \\ Cedex, France; ${ }^{3}$ Laboratoire ECOSYM, UMR 5119 CNRS-UM2-IRD-IFREMER, Place Eugène Bataillon cc 93, \\ Montpellier 34095, France; ${ }^{4}$ Muséum National d'Histoire Naturelle, CNRS UMR 7179 Mecadev, 4 avenue du Petit- \\ Château, 91800 Brunoy, France; and ${ }^{5}$ Faculdade de l'Agronomia, Departemento de Ciência do Solo, Universidade \\ Federal do Rio Grande do Sul, Av. Bento Gonçalves, 7712, 91540-000 Porto Alegre, Brazil
}

\section{Summary}

1. Trait-based approaches have the potential to reveal general and predictive relationships between organisms and ecosystem functioning. However, the mechanisms underlying the functional structure of communities are still unclear. Within terrestrial ecosystems, several studies have shown that many ecological processes are controlled by the interacting above- and belowground compartments. However, few studies have used traits to reveal the functional relationships between plants and soil fauna. Mostly, research combining plants and soil fauna solely used the traits of one assemblage in predictive studies.

2. Above-ground (plants) and below-ground (Collembola) compartments were sampled over a flooding gradient in northern France along the Seine River. First, we measured the effect of flooding on functional and taxonomic assembly within both communities. We then considered the linkages between plant and Collembolan species richness, community traits and assessed whether traits of both compartments converged at high flooding intensity (abiotic filtering) and diverged when this constraint is released (biotic filtering).

3. Species richness of both taxa followed the same bell-shaped pattern along the gradient, while a similar significant pattern of functional richness was only observed for plants. Further analyses revealed a progressive shift from trait convergence to divergence for plants, but not for Collembola, as constraints intensity decreased. Instead, our results highlighted that Collembola traits were mainly linked to the variations in plant traits. This leads, within Collembola assemblages, to convergence of a subset of perception and habitat-related traits for which the relationship with plant traits was assessed.

4. Synthesis. Using a trait-based approach, our study highlighted that functional relationships occur between above- and below-ground compartments. We underlined that functional composition of plant communities plays a key role in structuring Collembola assemblages in addition to the role of abiotic variables. Our study clearly shows that functional diversity provides a new approach to link the above- and below-ground compartments and might, therefore, be further considered when studying ecological processes at the interface between both compartments.

Key-words: community assembly, environmental gradient, functional traits, microarthropod communities, null models, plant communities, soil-plant interactions, trait convergence and trait divergence

\footnotetext{
*Correspondence author. E-mail: corentin.abgrall1@univ-rouen.fr
}

${ }^{\dagger}$ Both authors contributed equally to this work. 


\section{Introduction}

With the urgent need of a predictive ecology, focusing on traits rather than species identities has contributed to a better understanding of general relationships linking communities to environments regardless of their species composition (McGill et al. 2006; Messier, McGill \& Lechowicz 2010). The analysis of trait distribution within and among plant and animal communities has shed light on different filtering processes and constraints on community assembly along environmental gradients (Violle et al. 2012; Podgaiski et al. 2013). Competition and other biotic interactions are expected to lead to trait overdispersion, or divergence, within a community as coexistence is dependent on the limitation of similarities in resource use among species (MacArthur \& Levins 1967; Pillar et al. 2009). Conversely, strong abiotic filters are expected to generate an underdispersed, or convergent, trait distribution by constraining the range of possible trait values (Cornwell, Schwilk \& Ackerly 2006; Pillar et al. 2009). Despite the recent advances in trait-based community ecology, there are still debates regarding the relative importance of environmental filters especially at small scale where local dispersal (stochastic process) and biotic interactions (deterministic process) may prevail over abiotic environmental constraints (Bell 2005; Bernard-Verdier et al. 2012; Widenfalk et al. 2015).

Terrestrial ecosystems are composed of two interdependent compartments: above- and below-ground (Hooper et al. 2000). We are increasingly learning that soil biota is closely related to above-ground plant communities (Scheu 2001; Wardle, Bardgett \& Klironomos 2004). There is compelling evidence that soil biota is responsive to the quality and quantity of organic matter inputs as well as to the changes in microenvironmental conditions associated with changes in plant diversity (Wardle, Bardgett \& Klironomos 2004). As a feedback, by degrading litter, the below-ground compartment, for example, controls nutrients availability for plants (Bardgett \& Chan 1999). By doing so, the soil invertebrate fauna can also structure plant communities (Bonkowski \& Roy 2012) and succession dynamics (De Deyn et al. 2003), and therefore ecosystem properties, through modifications of plant competitive ability through antagonistic and mutualistic relationships (Wardle, Bardgett \& Klironomos 2004). As a consequence, these interactions between soil fauna and plants are central in regulating ecosystem processes such as soil respiration (Heemsbergen et al. 2004; Coleman \& Whitman 2005) and litter mass loss (Heemsbergen et al. 2004; Cornwell et al. 2008). All these contribute to global processes such as carbon cycling (Schlesinger \& Andrews 2000). The importance of these above-ground-below-ground interactions in the structuring of terrestrial ecosystems makes the concurrent study of both compartments extremely useful when evaluating ecosystem processes or community dynamics.

The relationship between functional traits and various environmental gradients has been extensively studied for plants (e.g. Cornwell \& Ackerly 2009; Violle et al. 2011; Bernard-Verdier et al. 2012; Mason et al. 2012), but less for the soil fauna (e.g. Ribera et al. 2001; Lambeets et al. 2009; Hedde, Van Oort \& Lamy 2012; Salmon \& Ponge 2012; Salmon et al. 2014). Few studies assessed the relationships between two trophic levels in relation to environmental gradients using a trait-based approach (e.g. Moretti \& Legg 2009; Frenette-Dussault, Shipley \& Hingrat 2013; Fournier et al. 2015). Some have, nonetheless, demonstrated a strong impact of plant functional composition on soil fauna or surface-dwelling arthropods (Frenette-Dussault, Shipley \& Hingrat 2013; Gorman et al. 2013; Pakeman \& Stockan 2014). Most of this research combining plants and soil fauna either used plant traits to explain faunal taxonomic composition or used vegetation structure and composition to explain the changes in faunal traits (Gorman et al. 2013; Podgaiski et al. 2013). However, none of them combined both analyses, which is what we intend to do in this study by focusing on both above- and below-ground traits.

We thus selected a flooding gradient, first because it is a main disturbance world-wide drastically impacting ecosystem properties and functioning (Allan \& Castillo 2007). Secondly, it offers the opportunity to have a clear abiotic gradient known to impact both plants (Lite, Bagstad \& Stromberg 2005; Violle et al. 2011) and below-ground fauna (Russell \& Griegel 2006; Lessel, Marx \& Eisenbeis 2011; Sterzyńska, Shrubovych \& Kaprus 2014). Belowground, we considered Collembola as a model group. They are abundant and diverse within soils (Hopkin 1997; Coleman, Crossley \& Hendrix 2004) and sensitive to the changes in soil abiotic variables such as soil organic matter, humidity and porosity (Joosse 1981; Didden 1987; Hasegawa 2002; Makkonen et al. 2011; Bokhorst et al. 2012). They also show close links with plant traits (Scheu, Theenhaus \& Jones 1999; Salamon et al. 2004; Endlweber \& Scheu 2006). Finally, Collembola are functionally important with respect to nitrogen cycling and plant growth (Filser 2002; Forey, Coulibaly \& Chauvat 2015).

We hypothesized a strong relationship between aboveground (herbaceous species) and below-ground (Collembola) compartments along a riparian flooding gradient and tested whether (i) the assembly (taxonomic and functional) of plant and Collembola is affected by the flooding gradient; (ii) there are clear linkages between the traits of Collembola communities and plant traits; (iii) traits of both compartments converge at high flooding intensity (abiotic filter) and diverge where this constraint is released (biotic filter).

\section{Materials and methods}

\section{STUDY SITE}

The study area was located on the banks of the Seine River (France) around the town of Petiville $(49.4611 \mathrm{~N}, 0.5883 \mathrm{E})$. Although the area is $20 \mathrm{~km}$ away from the estuary (English 
Channel), the tidal range is still between $3 \mathrm{~m}$ (neap tide) and $6 \mathrm{~m}$ (spring tide) due to the very flat slope on the last part of the river (Guézennec et al. 1999). Thus, this riparian area offers a good opportunity to study periodic flooding caused by tides. The mean annual temperature ranged from 8 to $12{ }^{\circ} \mathrm{C}$, and the mean annual rainfall from 600 to $1000 \mathrm{~mm}$.

The vegetation closest to the riverside was herbaceous and dominated by sedges (Cyperaceae: Scirpus sp. or Eleocharis sp.) generally followed by a monospecific reed bed [Phalaris arundinacea L. or Phragmites australis (Cav.) Trin. ex Steud.]. Willow groves (Salix sp.) with a typical riparian transition understorey were present at intermediate distances from the riverside. Poplars (Populus sp.) characterized the community closest to the dike (about $150 \mathrm{~m}$ from the river) protecting the floodplain from direct flooding. Thirty sampling units were placed at the study site. They were located to cover the widest possible range of hydrological, pedological, topographical and floral conditions with a minimal distance of $20 \mathrm{~m}$ separating them. Each of these units was sampled for plants, Collembola and several abiotic variables.

\section{ABIOTIC VARIABLES}

In order to quantify flood intensity between the different sampling units, we monitored volumetric water content for 3 months using field sensors (EC-5 soil moisture sensor, Decagon Devices) and data loggers (EM5B analog data logger, Decagon Devices). At each sampling unit, bulk of soil up to a depth of $10 \mathrm{~cm}$ was extracted and kept in plastic bags for transportation to the laboratory. Soil samples were air-dried and sieved at $2 \mathrm{~mm}$. The $\mathrm{pH}$ $\left(\mathrm{H}_{2} \mathrm{O}\right)$ was measured according to NF ISO 10390. Granulometry was assessed without sample decarbonatation for three fractions: clay, silt and sand (NF X 31-107). Limestone (CaCO3) content was measured using a Bernard calcimeter (NF ISO 10693). Total carbon and total nitrogen contents were measured by elemental analysis (NF ISO 10694 \& NF ISO 13878). A correction was made with limestone content to determine organic carbon content. Cobaltihexamine was used to assess the exchangeable cations ( $\mathrm{K}$ and $\mathrm{Mg}$ ) (NF X 31-130). Total conductivity was assessed using a ratio of 1 mass unit for 5 volume units. Canopy openness was evaluated visually during vegetation sampling and used to assess understorey light availability. These results were compiled in an abiotic variables matrix (E, 30 sampling units $\times 12$ abiotic variables).

\section{VEGETATION}

Within each sampling unit, a $2 \times 2 \mathrm{~m}$ quadrat was randomly placed and subdivided into four $1 \times 1 \mathrm{~m}$ subquadrats. Vascular plant species were identified within each quadrat in June 2011. In each of the four subquadrats, we counted presence-absence $(0 / 1)$ of each species. Then for each species, we summed those scores leading to an occurrence value per quadrat ranging from 0 to 4 . Relative contribution of each species per quadrat was calculated by dividing the single species occurrence value by total species occurrence value for a given quadrat. Species with total abundance accounting for less than $5 \%$ of total abundance were ignored for analysis (Cornelissen et al. 2003). Trait data were obtained from the TRY Plant Trait Database (Kattge et al. 2011). Individual data sets within the data base are referenced in Appendix S1 (Supporting Information). Multiple traits were selected supposedly reflecting different potential plant responses to flooding such as nutrient acquisition (vegetative/generative reproduction; Pérez-Harguindeguy et al. 2013), litter decomposability [leaf nitrogen content (LNC), lead dry matter content (LDMC); Fortunel et al. 2009], submersion tolerance [specific leaf area (SLA); Voesenek et al. 2006; plant height, Grime's CSR strategies,
Raunkier's life-forms], competitive ability (leaf area, plant height; Westoby et al. 2002), productivity (SLA; Lavorel et al. 2007), population recovery speed (seed mass, CSR strategies; Violle et al. 2011) and salinity tolerance (Ellenberg's value for salt tolerance). The qualitative variables were split into dummy variables for analysis (Table 1). Data were stored in two separate matrices: plant relative abundance $\left(\mathbf{W}_{\mathrm{V}}, 30\right.$ sampling units $\times 30$ species $)$ and plant traits $\left(\mathbf{B}_{\mathrm{V}}, 30\right.$ species $\times 21$ traits $)$.

\section{SOIL COLLEMBOLA}

Soil Collembola were sampled twice, in May and July 2011 at each sampling unit (i.e. vegetation quadrat) by taking a soil core (diameter: $5 \mathrm{~cm}$, depth: $10 \mathrm{~cm}$ ) using a steal corer and were stored in plastic bags and cool boxes for transportation to the laboratory. Collembola were then extracted for 15 days by the dry-funnel method before being counted and identified at the species level following several keys (Gisin 1943; Hopkin 2007). Data for both

Table 1. Vegetation traits used for analysis (Source: TRY data base)

\begin{tabular}{|c|c|c|c|}
\hline Traits & Code & Type & Attributes \\
\hline \multirow[t]{4}{*}{ Leaf texture } & LTHE & Binary & $\begin{array}{l}\text { Helomorphic } \\
\text { (1) or not }(0)\end{array}$ \\
\hline & LTHD & Binary & $\begin{array}{l}\text { Hydromorphic } \\
\text { (1) or not (0) }\end{array}$ \\
\hline & LTHG & Binary & $\begin{array}{l}\text { Hygromorphic } \\
\text { (1) or not (0) }\end{array}$ \\
\hline & LTM & Binary & $\begin{array}{l}\text { Mesomorphic } \\
\text { (1) or not (0) }\end{array}$ \\
\hline \multirow[t]{5}{*}{$\begin{array}{r}\text { Raunkier's } \\
\text { life-forms }\end{array}$} & $\mathrm{CHA}$ & Binary & $\begin{array}{l}\text { Chamaephyte } \\
\text { (1) or not (0) }\end{array}$ \\
\hline & HEL & Binary & $\begin{array}{l}\text { Helophytes (1) } \\
\text { or not }(0)\end{array}$ \\
\hline & GEO & Binary & $\begin{array}{l}\text { Geophytes (1) } \\
\text { or not (0) }\end{array}$ \\
\hline & PHA & Binary & $\begin{array}{l}\text { Phanerophytes } \\
\text { (1) or not (0) }\end{array}$ \\
\hline & THE & Binary & $\begin{array}{l}\text { Therophyte (1) } \\
\text { or not (0) }\end{array}$ \\
\hline \multirow[t]{2}{*}{$\begin{array}{l}\text { Species reproduction } \\
\text { type }\end{array}$} & REPG & Binary & $\begin{array}{l}\text { Generative (1) } \\
\text { or not (0) }\end{array}$ \\
\hline & REPV & Binary & $\begin{array}{l}\text { Vegetative (1) } \\
\text { or not }(0)\end{array}$ \\
\hline \multirow{3}{*}{$\begin{array}{l}\text { Grime's plant } \\
\text { strategies } \\
\text { (Grime 2001) }\end{array}$} & $\mathrm{C}$ & Binary & $\begin{array}{l}\text { Competitor (1) } \\
\text { or not }(0)\end{array}$ \\
\hline & S & Binary & $\begin{array}{l}\text { Stress tolerator } \\
\text { (1) or not (0) }\end{array}$ \\
\hline & $\mathrm{R}$ & Binary & $\begin{array}{l}\text { Ruderal (1) or } \\
\operatorname{not}(0)\end{array}$ \\
\hline Leaf area & LA & Numerical & $\mathrm{mm}^{2}$ \\
\hline Specific leaf area & SLA & Numerical & $\mathrm{mm}^{2} \mathrm{mg}^{-1}$ \\
\hline Leaf nitrogen content & $\mathrm{LNC}$ & Numerical & $\begin{array}{l}\% \mathrm{~N} \text { per leaf dry } \\
\text { mass }\end{array}$ \\
\hline Leaf dry matter content & LDMC & Numerical & $\mathrm{mg} \mathrm{g}^{-1}$ \\
\hline Plant vegetative height & PLH & Numerical & $\mathrm{cm}$ \\
\hline Seed dry mass & SDM & Numerical & g per 1000 seeds \\
\hline $\begin{array}{l}\text { Ellenberg's value } \\
\text { for salt tolerance } \\
\text { (Ellenberg et al. 1991) }\end{array}$ & ELL & Integer & $\begin{array}{l}0 \text { (absent from } \\
\text { saline sites) to } \\
9 \text { (species of } \\
\text { extremely saline } \\
\text { conditions) }\end{array}$ \\
\hline
\end{tabular}


sampling dates were averaged in a single matrix. Trait data were obtained from the COLTRAIT data base (Salmon \& Ponge 2012; Salmon et al. 2014). Selected traits were representative of dispersion capacity (leg length relative to body length, furca length, pigmentation), defence mechanisms (the number of pseudocelli; Hopkin 2007) and resource management [the number of ocelli, the number of post-antennal organ (PAO) lobes]. Unordered qualitative variables were split into dummy variables for analyses (Table 2). Data were stored in two separate matrices: Collembola relative abundance $\left(\mathbf{W}_{\mathbf{C}}, 30\right.$ sampling units $\times 21$ species $)$ and Collembola traits $\left(\mathbf{B}_{\mathrm{C}}, 21\right.$ species $\times 12$ traits).

\section{DATA ANALYSIS}

\section{Abiotic gradient analysis}

Regular tidal flooding has a variety of effects on soil properties (i.e. regular waterlogging and drainage, concentration of various elements, soil texture). In order to characterize the gradient and positioning our sampling units along a single axis, we performed a principal component analysis (PCA) on matrix $\mathbf{E}$ (Fig. 1). The first two components accounted for $81 \%$ of data variability (50.1\% and $30.9 \%$, respectively). Flooding intensity was strongly correlated with the first axis (94\%), making the first component representative of flooding-induced changes. Other abiotic variables were also strongly correlated with this axis, such as soil $\mathrm{pH}$, soil organic matter and soil total nitrogen. We used the sampling units scores on the first component of the PCA as a synthetic variable incorporating multiple abiotic variables and representative of a flooding gradient. Thereafter, in this study, the terms 'flooding gradient' and 'flooding intensity' will refer to this synthetic abiotic variable ranging from maximum (left side of the axis 1) to minimum (right side of the axis 1) flooding. For clarity, the gradient will, thereafter, be represented on figures with the same symbol used in Fig. 1.

Table 2. Collembola traits used in this study (Source: Coltraits data base, S. Salmon)

\begin{tabular}{|c|c|c|c|}
\hline Traits & Code & Type & Attributes \\
\hline Furca length & LFU & $\begin{array}{l}\text { Ordered } \\
\text { factor }\end{array}$ & $\begin{array}{l}\text { Absent }(0) \text {, } \\
\text { rudimentary (1), } \\
\text { reduced (2), average } \\
(3), \text { long (4) }\end{array}$ \\
\hline \multirow[t]{3}{*}{ Shape } & CYL & Binary & $\begin{array}{l}\text { Cylindrical (1) or } \\
\text { not (0) }\end{array}$ \\
\hline & THK & Binary & Thickset (2) or not (0) \\
\hline & GLO & Binary & Globular (3) or not (0) \\
\hline Scales & SCA & Binary & Present (1), absent (0) \\
\hline Pigmentation & PIGM & Binary & Present (1), absent (0) \\
\hline $\begin{array}{l}\text { Antenna length } \\
\text { relative to head } \\
\text { diagonal length }\end{array}$ & LANT & Numerical & Ratio \\
\hline $\begin{array}{l}\text { Leg length relative } \\
\text { to body length }\end{array}$ & LLBC & Numerical & Ratio \\
\hline Body length & LEN & Numerical & $\mathrm{mm}$ \\
\hline $\begin{array}{l}\text { The number of } \\
\text { post-antennal } \\
\text { organs lobes }\end{array}$ & LPAO & Integer & \\
\hline $\begin{array}{l}\text { Mean number of } \\
\text { pseudocellula }\end{array}$ & PSTO & Integer & \\
\hline $\begin{array}{l}\text { The number of } \\
\text { ocelli }\end{array}$ & OCE & Integer & \\
\hline
\end{tabular}

\section{Functional and taxonomic patterns}

Species richness (Ric) was calculated for plants and Collembola at each sampling point. Functional diversity was assessed separately for plants and Collembola using the three complementary indices of Villéger, Mason \& Mouillot (2008): functional richness (FRic), functional evenness (FEve) and functional divergence (FDiv). Prior to the calculation of indices, we performed a principal coordinates analysis $(\mathrm{PCoA})$ on a corrected species-by-species distance matrix with possible dimensionality reduction. FRic was then computed by finding the minimum convex hull volume that includes all species coordinates and therefore represents the volume occupied by a given community in the functional space. FEve measures the regularity of the distribution of abundance in functional space. FDiv is defined by the degree of maximization of dissimilarities between functional species and their abundance in functional space. These indices were calculated using the 'FD' $R$ package (Laliberté, Legendre \& Shipley 2014). We attempted to relate these indices to the flooding gradient using generalized linear model (GLM). Diversity indices were log-transformed to meet the assumption of normality when required. Details on model selection for each index as well as the coefficients of significant regressions are provided in Appendix S2. All statistical analyses were performed using $\mathrm{R}$ software version 3.1.3 (R Core Team 2015). The significant level for all analyses was $P<0.05$.

\section{Trait assembly patterns and intertaxa trait relationships}

Trait-convergence and trait-divergence assembly patterns were assessed using the 'TCAP/TDAP' method proposed by Pillar et al. (2009). A trait-convergence assembly pattern (TCAP) can be identified when sites nearby on an ecological gradient consistently contain species with similar traits. Conversely, a trait-divergence assembly pattern (TDAP) can be observed when the turnover in trait-based community components is related to the gradient but with communities containing species with dissimilar traits. For details regarding TCAP/TDAP calculation as applied here, see Appendix S3. We then used iterative process aimed at finding an optimal subset of traits that maximizes convergence, divergence or both (see Pillar \& Sosinski Jr. 2003; for details). We initially assessed TCAP and TDAP within plants and Collembola communities in relation to the environmental variables. In addition, we used plants community-weighted trait means (CWM) as an environmental matrix in order to assess the plant-induced trait convergence or trait divergence within Collembola communities. All TCAP and TDAP computations were performed using the 'SYNCSA' R package (Debastiani \& Pillar 2012).

While the TCAP/TDAP approach gives information on the nature of the patterns structuring community assemblages, it does not reveal the position of those patterns along the flooding gradient. In that regard, we computed mean pairwise distances (MPD) within communities $\left(\mathbf{W}_{\mathrm{V}}\right.$ or $\mathbf{W}_{\mathrm{C}}$ ) based on species traits (pairwise functional distances matrix $\mathbf{D}_{\mathrm{B}}$ defined by calculating Gower's distances on matrix B). These MPDs were assessed for non-random patterns by testing against a null model. This model involved random permutations of species names within the pairwise distance matrix maintaining community taxonomic structure with randomized functional structure. Final 'random MPD' value describes a community devoid of convergence or divergence patterns. Differences between observed MPDs and random MPDs were used to identify either convergence or divergence for each community along the flooding gradient. We initially tested plants and Collembola communities against the null model using all their traits. Subsets of traits previously found to maximize convergence (TCAP), divergence (TDAP) or both were then used to test for non-randomness within the communities. A generalized linear model (GLM) was fitted on the data with the flooding gradient as 


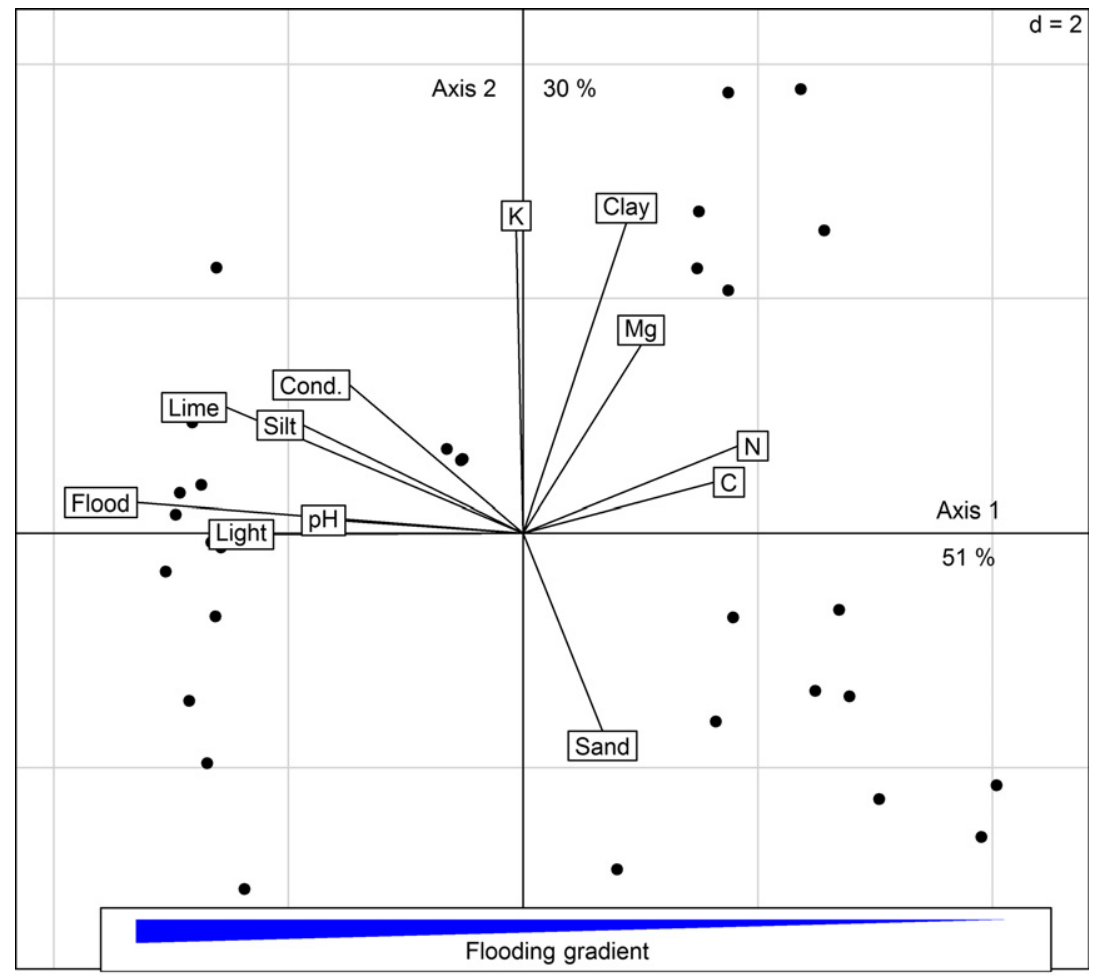

(a)

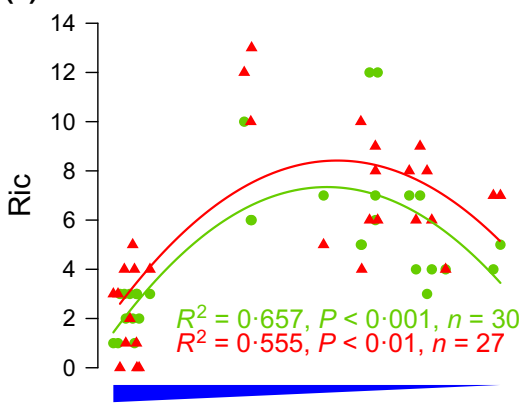

Flooding gradient
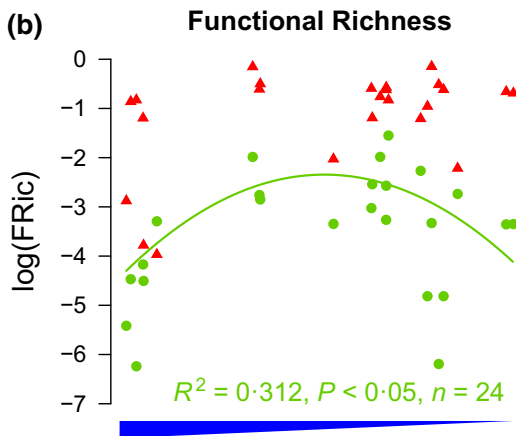

Flooding gradient
Fig. 1. Principal component analysis (PCA) ordination diagram of plots based on soil abiotic parameters. Points are sampling units. $\mathrm{C}, \mathrm{N}, \mathrm{K}, \mathrm{Mg}$ : carbon, nitrogen, potassium and magnesium content. Silt, Clay, Sand: soil granulometry, $\mathrm{pH}: \mathrm{pH}$ $\mathrm{H}_{2} \mathrm{O}$, Light: canopy openness proportion, Lime: $\mathrm{CaCO}_{3}$ content, Cond.: conductivity and Flood: proportion of time with saturated water content. The blue polygon is used to represent the flooding gradient in other figures.

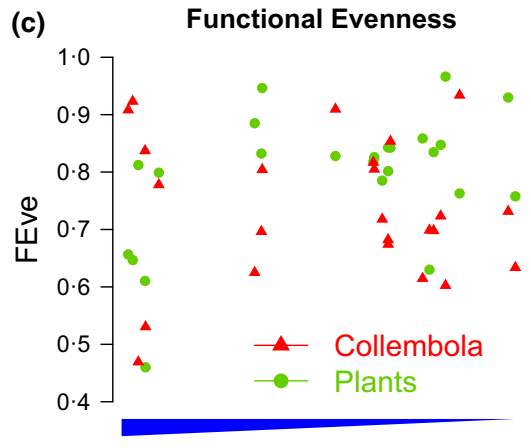

Flooding gradient

Fig. 2. Taxonomic and functional richness and evenness of vegetation (green points and line) and Collembola (red points and lines). (a) Taxonomic richness (Ric); (b) functional richness (FRic); (c) functional evenness (FEve). The flooding gradient explanatory variable is a synthetic index extracted from the PCA scores of sampling units on the principal component. $R^{2}$ values were not shown when not significant.

explanatory variable. This was done, for both plants and Collembola, using all their traits as well as the trait subset found to maximize both trait convergence and trait divergence in relation to the environmental data set. This was possible due to the synthetic flooding gradient's linearity. Plant CWMs used in the TCAP/ TDAP analysis as environmental conditions likely to structure Collembola communities could not be reduced to such a variable. Thus, for Collembola, we assessed significant differences in the median from 0 using a Wilcoxon one-sample test in order to confirm either a convergent (if significantly negative) or divergent (if significantly positive) trait assembly pattern. All MPD computations were done using the 'PICANTE' $\mathrm{R}$ package (Kembel et al. 2010).

In order to link plant traits that promote convergence of the Collembolan community, we performed a principal component analysis (PCA) on the subset of Collembolan traits exhibiting a trait-convergence assembly pattern in response to changes in community-weighted means of plant traits. Plant CWMs were added as supplementary variables to the analysis to reveal the linkages between above- and below-ground traits.

\section{Results}

\section{DIVERSITY PATTERNS}

The relationship between taxonomic richness and flooding gradient (axis 1 of the PCA) demonstrated that plant $\left(R^{2}=0.657, P<0.001, n=30\right.$; Fig. 2a) and Collembola $\left(R^{2}=0.555, P<0.01, n=27\right.$; Fig. 2a) species richness showed a unimodal response to disturbance intensity. Plant functional richness also showed a unimodal response to disturbance intensity (quadratic relationships: 
$R^{2}=0.312, P<0.05, n=24$; Fig. 2b), which was not observed for Collembola (functional richness: $R^{2}=0 \cdot 172$, $P=0 \cdot 256, n=24$, Fig. 2b). Plant functional evenness did not match any known probability distribution and could not be regressed. Collembola functional evenness was successfully modelled in response to the flooding gradient, but no significant pattern could be found $\left(R^{2}=0.042\right.$, $P=0.460, n=24$, Fig. 2c). No model was able to explain plant or Collembola functional divergence along the flooding gradient $\left(R^{2}=0.033, \quad P=0.403, \quad n=24 \quad\right.$ and $R^{2}=0.031, P=0.398, n=24$, respectively).

\section{TRAIT-CONVERGENCE AND TRAIT-DIVERGENCE ASSEMBLY PATTERNS}

The flooding gradient induced maximum convergence ( $\varrho=0.666, P=0.002$, Table 3 ) in a subset of plant traits containing leaf nitrogen content (LNC), mesotrophic leaf texture (LTM) and a ruderal strategy (R). The same subset of traits with the addition of leaf dry matter content (LDMC) also maximized both convergence and divergence ( $\varrho=0.668, P=0.001$, Table 3). Maximum divergence ( $\varrho=0.630, P=0.001$, Table 3 ) was detected for a subset of traits composed of $\mathrm{LNC}, \mathrm{LDMC}, \mathrm{R}$ and vegetative reproduction (REPV). No subset of Collembolan traits was found to maximize either convergence or divergence using the flooding gradient as explanatory factor (Table 3). However, the use of plant functional traits (community-weighted means, matrix T) as an explanatory variable led to significantly maximized convergence ( $\varrho=0.467, P=0.025)$ of a subset of Collembolan traits: legs length relative to body length (LLBL), the number of PAO lobes (LPAO) and a globular or cylindrical shape (GLO or CYL).

\section{FUNCTIONAL MEAN PAIRWISE DISTANCE WITHIN PLOTS}

Differences between observed and null functional mean pairwise distances within plant communities showed no significant relationship with the flooding gradient when using all traits (quadratic relationship: $R^{2}=0 \cdot 30$, $P=0 \cdot 146, n=27$, Fig. 3). When using plant traits maximizing both trait convergence and divergence along the gradient (LA, LNC, LTM and R, see Tables 1 and 3), we demonstrated a significant positive relationship with the flooding gradient (linear relationship: $R^{2}=0.75$, $P<0 \cdot 0001, n=27$, Fig. 3). Similarly, using all Collembola traits in relation to the gradient, we did not detect any apparent pattern (linear relationship: $R^{2}=0 \cdot 163$, $P=0.437, n=25$ ) and no significant difference from 0 (i.e. random expectations; $V=191, P=0.458$, Fig. 4), suggesting an absence of trait convergence or divergence. When using the Collembola subset of traits maximizing trait convergence and divergence (i.e. LLBL, LPAO, CYL and GLO, see Tables 2 and 3) in relation to the variations in plant traits community-weighted means (matrix $\mathbf{T}$ ), we demonstrated a significant difference from $0 \quad(V=37$, $P<0.001$ ), indicating lower-than-expected mean pairwise distances, that is trait convergence. No significant relation was found between Collembolan MPDs for the trait subset and the flooding gradient (linear relationship: $R^{2}=0.113$, $P=0.066, n=27$, Fig. 3).

\section{LINKAGES BETWEEN COLLEMBOLAN AND PLANT TRAITS}

Along the first $(52.98 \%$ of explained variance) and second (30.48\% of explained variance) component of the PCA, Collembolan traits shown to converge were clearly separated into two groups, LPAO and GLO on one side and PIGM and LLBL on the other side (Fig. 5). Each of these groups was closely associated with different plant traits. Positive values of LPAO and GLO Collembolan traits were related to positive SLA, LNC, LTM, LTHG, C and R values on the first component. Inversely, positive PIGM and LLBL values were related to positive LDMC, SDM, PLH, ELL, LTHD, LTHE and $S$ values.

Table 3. Trait-convergence and trait-divergence assembly patterns for vegetation and Collembola using Pillar index (Pillar et al. 2009). Subsets of traits that maximize trait-convergence assembly patterns (TCAP), trait-divergence assembly patterns (TDAP) or both (TCAP/ TDAP) are given in italic. See Tables 1 and 2 for details on traits. Ro gives the result of a correlation test analogous to a standardized Mantel test (1967) between explained matrices (traits combined with abundance) and the explanatory matrix. Values in bold indicate significant result $(P<0 \cdot 05)$, while values in grey indicate non-significant results $(P \geq 0 \cdot 05)$

\begin{tabular}{|c|c|c|c|c|c|c|c|}
\hline \multirow{2}{*}{$\begin{array}{l}\text { Explained } \\
\text { matrices }\end{array}$} & \multirow[b]{2}{*}{ Explanatory matrix } & \multicolumn{2}{|c|}{ TCAP } & \multicolumn{2}{|c|}{ TDAP } & \multicolumn{2}{|c|}{ TCAP/TDAP } \\
\hline & & ro & $P$ & ro & $P$ & ro & $P$ \\
\hline \multirow[t]{2}{*}{ Vegetation } & \multirow[t]{2}{*}{ Abiotic environment } & $L N C$ & & \multicolumn{2}{|c|}{$L N C L D M C R R E P V$} & \multicolumn{2}{|c|}{$L N C L D M C L T M R$} \\
\hline & & $0 \cdot 666$ & $0 \cdot 002$ & $0 \cdot 630$ & $0 \cdot 001$ & $0 \cdot 668$ & $0 \cdot 001$ \\
\hline \multirow[t]{2}{*}{ Collembola } & \multirow[t]{2}{*}{ Abiotic environment } & $\angle P A O$ & & \multicolumn{2}{|c|}{ PIGM VIS } & \multicolumn{2}{|c|}{ VIS PSTO } \\
\hline & & $0 \cdot 321$ & $0 \cdot 135$ & $0 \cdot 282$ & $0 \cdot 084$ & 0.079 & $0 \cdot 250$ \\
\hline \multirow[t]{2}{*}{ Collembola } & \multirow{2}{*}{$\begin{array}{l}\text { Vegetation traits } \\
\text { community-weighted } \\
\text { means }\end{array}$} & \multicolumn{2}{|c|}{ LLBL LPAO PIGM GLO } & \multicolumn{2}{|c|}{ LFUR LANT OCE THK } & \multicolumn{2}{|c|}{ LANT OCE GLO } \\
\hline & & $0 \cdot 435$ & $0 \cdot 039$ & $0 \cdot 437$ & $0 \cdot 203$ & 0.433 & $0 \cdot 089$ \\
\hline
\end{tabular}




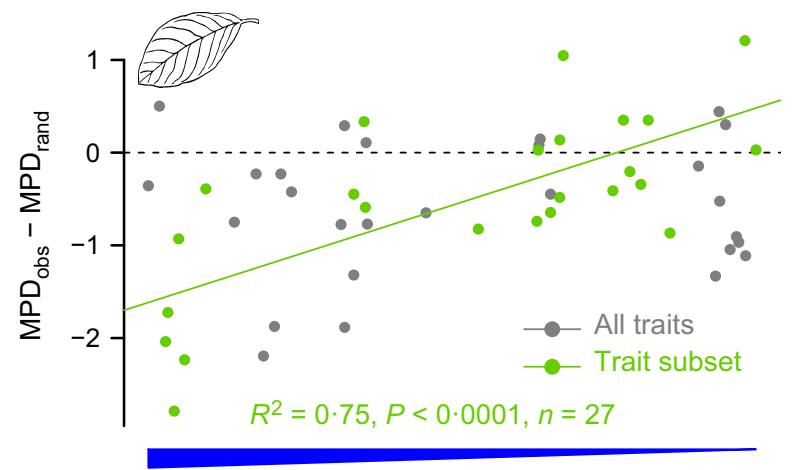

Flooding Intensity

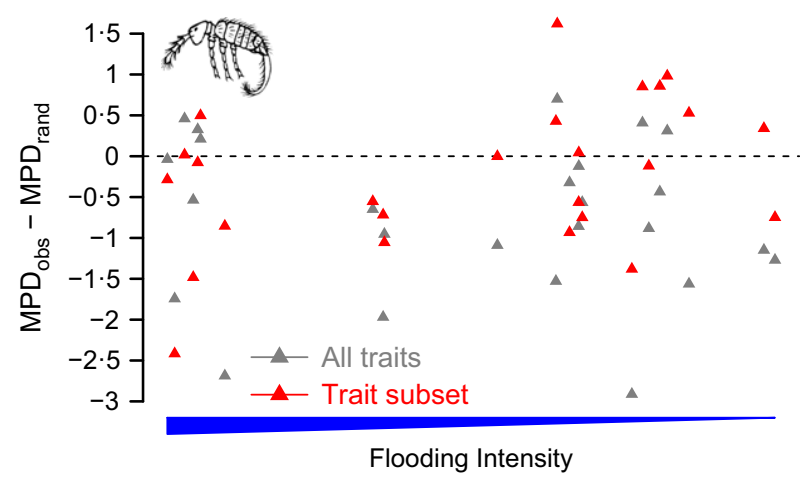

Fig. 3. Differences between observed and null functional mean pairwise distances (MPD) within plant (points) and Collembolan (triangles) communities along the gradient. Grey: distances calculated using all traits; green/red: distances calculated using the trait subset determined to maximize convergence and divergence in vegetation traits along the gradient (LNC, LDMC, LTM and R, see Tables 1 and 3). Dashed line represents the limit between a convergent and divergent pattern. Solid lines are significant regressions for the corresponding data. $R^{2}$ values were not shown when not significant.

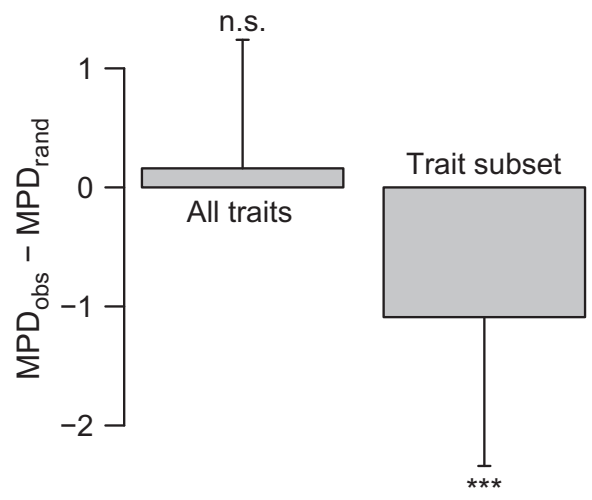

Fig. 4. Differences between observed (MPD.obs) and random (MPD.rand) mean pairwise distances (MPD) within Collembola communities. All traits: distances calculated using all Collembolan traits; trait subset: distances calculated using the trait subset determined to maximize convergence in Collembola traits in relation to the community-weighted mean of vegetation traits (LLBL, LPAO, PIGM \& GLO, see Tables 2 and 3). Asterisks indicate significant differences after a Wilcoxon onesample test between observed values and 0 (n.s.: $P>0.05$, $* * * P<0.001)$.

\section{Discussion}

ABOVE- AND BELOW-GROUND DIVERSITIES ALONG THE GRADIENT

One of our aims was to assess the relationship between plant and Collembola taxonomic and functional diversities along a flooding gradient. A common response pattern between taxa was only revealed for taxonomic richness with a concave-down function. Other studies have already reported such a pattern along different flooding gradients either for plants (Lite, Bagstad \& Stromberg 2005; Violle et al. 2011) or for soil arthropods/Collembola (Lambeets et al. 2009). This pattern matches the intermediate disturbance hypothesis' of Connell (1978), which states that diversity of competing species is expected to be maximized at intermediate frequencies and/or intensities of constraints (but see Fox 2013). Diversity is supposedly limited for high and low disturbance (or stress) level due to two contrasting phenomena: abiotic environmental filtering and interspecific interactions, respectively. The first limits the number of species able to colonize and survive under harsh environmental conditions, while the second constrains species richness through, mostly, competitive exclusion (Wilson 2007).

Contrary to our expectations, Collembola functional diversity (i.e. all three indices) as well as plant functional evenness and divergence was not found to be directly affected by the flooding gradient. Patterns of stable functional diversity in relation to varying species richness have been observed for other taxonomic groups such as bats (Stevens et al. 2003) and explained by functional redundancy between species. Only plant functional richness responded to the flooding gradient with the same concavedown pattern as observed for taxonomic richness. This relation between taxonomic and functional diversity has been previously documented for plants (Villéger, Mason \& Mouillot 2008; Biswas \& Mallik 2010; Violle et al. 2011). In our case, taxonomic richness significantly explained $77 \%$ of the functional richness for plants, which is in the range of previous studies: $62 \%$ in Violle et al. (2011) and $87 \%$ in Villéger, Mason \& Mouillot (2008). Collembola functional richness was also correlated but only slightly significantly $(56 \%)$ with Collembola species richness. While this relationship for soil fauna was not assessed in the literature, Fournier et al. (2012) investigating earthworms in restored floodplains identified congruent patterns of species richness and functional trait diversity. However, Gerisch et al. (2012) investigating the response of ground beetles to flood disturbance found an opposite pattern of taxonomic species richness and functional diversity. They concluded that flooding disturbance increased the number of species but that species were functionally redundant. The discrepancy between taxonomic and functional patterns for soil fauna could also be explained by stochastic movements of soil fauna communities (in our case Collembola) along the gradient governed by water run-offs or tides, contrary to plants anchored in the soil. Lastly, we cannot exclude that the lack 
Fig. 5. Principal component analysis (PCA) of community-weighted Collembola traits exhibiting a trait-convergence assembly pattern (TCAP): 'pigm', 'llbl', 'glo' and 'Ipao'. Community-weighted plant traits (in uppercase) were added as supplementary, or explanatory variables.

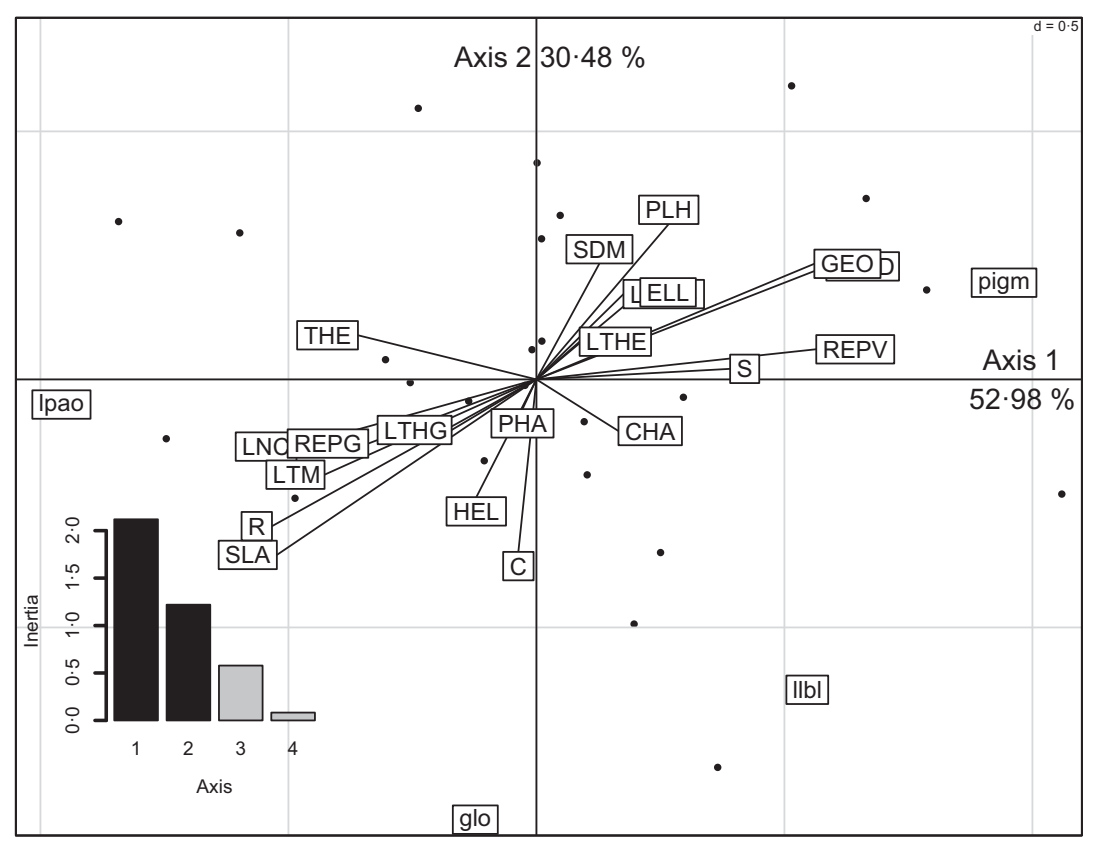

of functionality of the considered faunal traits (especially the lack of ecophysiological traits) in relation to flooding may obviate for detecting strong relationship between species richness and functional richness.

\section{TRAIT PATTERNS AND DRIVERS WITHIN COMMUNITY ASSEMBLAGES}

Having evaluated for the existence of patterns of functional diversity along the flooding gradient, we then assessed the relative importance of trait convergence and divergence in relation to the abiotic variables characterizing the gradient.

Regarding plants, we demonstrated that environmental variations led to consistent trait convergence and trait divergence (i.e. TCAP and TDAP) within above-ground communities, suggesting that both abiotic and biotic filters structure plant communities. Analysis of mean pairwise distances (MPDs) enabled us to reveal the relative dominance of the two assembly patterns (i.e. TCAP and TDAP) along the gradient. Trait convergence, which prevailed when flooding intensity was maximal (Fig. 3), was maximized for a subset of traits known to have a strong influence on organic matter cycling (LNC; Fortunel et al. 2009), resistance to disturbance (R strategy; Grime 2001) and differentiating specialist from generalist species (LTM, R strategy). Consequently, communities observed for minimal flooding were dominated (Appendix S4) by opportunistic and generalist species (high rate of $\mathrm{R}$ strategy) with average leaf characteristics (high LTM) and improved competitive abilities with increased mass-based photosynthetic rate (high LNC and SLA; Cornelissen et al. 2003). This suggests a decrease in environmental, or abiotic, filtering with plant specialization towards resistance to water stress being directly related to flooding intensity.

As revealed by MPDs analysis, the assembly pattern shifts from trait convergence to trait divergence with the decrease in flooding intensity, further supporting a shift from abiotic filtering to biotic filtering within communities. Indeed, the trait-divergence assembly pattern observed at minimal flooding separates communities according to their resource allocation to leafs (LNC and LDMC), their life strategy (R) as well as their ability for vegetative reproduction (REPV), which can impact competitive interactions and resource prospection (Pérez-Harguindeguy et al. 2013). This reflects an increased degree of variation for mean trait values between communities less exposed to flooding. As per our initial hypothesis, this suggests a decrease in environmental trait filtering. A similar shift was found by Violle et al. (2011) for a limited number of traits, suggesting flooding gradient induced convergence in some traits as well as divergence caused by biotic interactions in others. Our results show once again that an abiotic gradient can significantly alter community functional structure.

Regarding Collembola, the TCAP/TDAP approach allowed us to demonstrate that only plant functional traits and not the considered abiotic filters explain their functional trait patterns. This result emphasizes the determinant role of plant characteristics and function for Collembola communities. While the considered environmental variables were found to be suitable to explain plant functional diversity, other soil properties could have proved to have more impact on Collembola. In addition, and contrary to plants that are anchored in the soil, Collembola have several behavioural mechanisms at their disposal in order to escape flooding. One such mechanism is passive drifting, which has been documented for the Protaphorura genus (Marx et al. 2009) in flooded riparian areas. Collembola have also been observed climbing on vertical surfaces in order to avoid the rising tide (M. Chauvat, personal observation), and some Collembolan species are known to climb on plants or tree trunks (Ponge 1993). Such mechanisms could reduce the need for morphological adaptations to flooding disturbance. This could limit 
the potential response of Collembola to flooding when only morphological traits are used. Such adaptations could explain a lack of a strong response of Collembola in our study, the considered morphological traits being only weakly filtered by abiotic variables.

A significant trait-convergence assembly pattern was identified among Collembola communities for a subset of morphological (LLBL, GLO), perception (LPAO) and habitat-related (PIGM) traits (Table 3) when considering community-weighted plant traits. This shows that Collembolan communities' functional assembly can be driven and filtered by their biotic environment through a limitation of trait variation. Under highly productive and disturbanceadapted plant communities (high SLA, LNC and low LDMC; Fig. 5; Cornelissen et al. 2003), we found Collembolan communities dominated by low-pigmented species with a high capacity for chemical perception (high LPAO; Ryan 2002) corresponding to deep soil-living organisms (Gisin 1943; Vandewalle et al. 2010). The high GLO values under the same plant communities reflect the common presence of two small species of Symphypleona (with globular body) Megalothorax minimus and Arrhopalites caecus. Highly productive plants, found at low flooding rate, may promote abundance of deep soil-living Collembola by improving trophic resources in the soil through delivery of high quality and quantity of litter. This was corroborated by the increased organic carbon and nitrogen content (Fig. 1) in low flooding sites. Conversely, Collembola communities under poor-quality litter (low SLA, LNC and high LDMC) were dominated by highly mobile (high LLBL) surface-dwelling species (high PIGM) able to forage further for the limited trophic resources (Chauvat, Perez \& Ponge 2014). Functionally, deep soil-living and surface-dwelling Collembola are different as they are traditionally ascribed to different life strategy with the surface species being rather r-strategists and the soil species more K strategists (Petersen 2002). Furthermore, deep soil-living species are often reported as having more effect than surface species on $\mathrm{C}$ and $\mathrm{N}$ cycling (Petersen 2002), possibly through a higher connection to soil microflora (Filser 2002).

For the first time, we clearly linked above-ground plant traits and Collembola traits despite the presence of a strong abiotic gradient (flooding). Previous studies had, however, already shown that Collembolan life-forms (groups based on traits; Gisin 1943) can be influenced by changes within plant community taxonomic structure (Salamon et al. 2004; Chauvat et al. 2011; Eisenhauer, Sabais \& Scheu 2011; Perez et al. 2013), indirectly suggesting a response of several Collembolan traits to plant traits. In this study, we only used epigeous plant traits when endogenous plant traits (i.e. root traits) could have been more appropriate for soil Collembola. However, several studies have demonstrated a strong correlation between leaf traits and their root counterpart (e.g. Craine, Froehle \& Tilman 2001), making them a valid proxy. Data on Collembolan feeding guilds would also have been particularly interesting and would have enabled us to assess the relationship between distinct guilds (especially preferential herbivores) and plant communities. Such data are, however, regrettably rare and heterogeneous (e.g. Berg, Stoffer \& Van Den Heuvel 2004; Chahartaghi et al. 2005). Nevertheless, we are confident that there is a strong linkage between plant and Collembolan communities through their traits. Indeed, the literature suggests the prime importance of abiotic conditions to filter Collembolan communities (e.g. Kardol et al. 2011; Makkonen et al. 2011; Bokhorst et al. 2012; Sterzyńska, Shrubovych \& Kaprus 2014), which was not observed here contrary to the influence of plants.

\section{Conclusion}

Combining a taxonomical and a trait-based approach allowed us to depict responses of both above-ground and below-ground compartments to a flooding gradient. We showed that both plant species and functional richness responded to the flooding gradient. We identified both trait-convergence and trait-divergence assembly patterns with varying flooding intensity. This showed a filtering of plant community assembly by abiotic parameters in perturbed environment and biotic filtering within more stable environmental conditions. While Collembola functional diversity proved unresponsive to the flooding gradient, community functional assembly was controlled through a subset of traits converging in response to plant traits at a community scale. We then clearly showed which plant traits were most responsible for the convergence within Collembolan traits. We believe that the use of functional traits in above-ground-below-ground studies should be further explored to improve our understanding of community assembly. Finally, more fundamental studies on soil fauna traits, quantifying both their responses to biotic and abiotic environmental conditions and their effect on ecological processes, are also required.

\section{Acknowledgements}

This study was financially supported by the REBEBAS project funded by the 'Groupement d'Intérêt Public Seine Aval' (GIP Seine-Aval - research programme Seine Aval IV 2008) and the 'Région Haute-Normandie' through the GRR-SER SCALE (UFOSE Project). We would like to thank all the members of the Ecodiv laboratory (University of Rouen), especially Dr Fabrice Bureau. We would also like to thank the anonymous reviewers for their time and constructive criticisms. The study has been supported by the TRY Initiative on Plant Traits ('http://www.try-db.org'). The TRY initiative and data base is hosted, developed and maintained by J. Kattge and G. Bönisch (Max Planck Institute for Biogeochemistry, Jena, Germany). TRY is currently supported by DIVERSITAS/Future Earth and the German Centre for Integrative Biodiversity Research (iDiv) Halle-Jena-Leipzig.

\section{Data accessibility}

Collembolan abundance data $\left(\mathbf{W}_{\mathbf{C}}\right)$ : DRYAD entry http://dx.doi.org/ 10.5061/dryad.kk744 (Abgrall et al. 2016).

Collembolan trait data $\left(\mathbf{B}_{\mathbf{C}}\right)$ : data available on request from the BETSI Database (http://betsi.cesab.org/) or from the COLTRAIT Database (http://www.bdd-inee.cnrs.fr/).

Plant relative frequency data $\left(\mathbf{W}_{\mathbf{V}}\right)$ : DRYAD entry http://dx.doi.org/ 10.5061/dryad.kk744 (Abgrall et al. 2016). 
Plant trait data $\left(\mathbf{B}_{\mathbf{V}}\right)$ : data available on request from the TRY Database (http://www.try-db.org).

Abiotic environmental data (E): DRYAD entry http://dx.doi.org 10.5061/dryad.kk744 (Abgrall et al. 2016)

\section{References}

Abgrall, C., Chauvat, M., Langlois, E., Hedde, M., Mouillot, D., Salmon, S. et al. (2016) Data from: Shifts and linkages of functional diversity between above and belowground compartments along a flooding gradient. Dryad Digital Repository, http://dx.doi.org/10.5061/dryad.kk744.

Allan, J.D. \& Castillo, M.M. (2007) Stream Ecology: Structure and Function of Running Waters. Springer Science \& Business Media, Heidelberg, Germany.

Bardgett, R.D. \& Chan, K.F. (1999) Experimental evidence that soil fauna enhance nutrient mineralization and plant nutrient uptake in montane grassland ecosystems. Soil Biology and Biochemistry, 31, 1007-1014.

Bell, G. (2005) The co-distribution of species in relation to the neutral theory of community ecology. Ecology, 86, 1757-1770.

Berg, M.P., Stoffer, M. \& Van Den Heuvel, H.H. (2004) Feeding guilds in Collembola based on digestive enzymes. Pedobiologia, 48, 589-601.

Bernard-Verdier, M., Navas, M.L., Vellend, M., Violle, C., Fayolle, A. \& Garnier, E. (2012) Community assembly along a soil depth gradient: contrasting patterns of plant trait convergence and divergence in a Mediterranean rangeland. Journal of Ecology, 100, 1422-1433.

Biswas, S.R. \& Mallik, A.U. (2010) Disturbance effects on species diversity and functional diversity in riparian and upland plant communities. Ecology, 91, 28-35.

Bokhorst, S., Phoenix, G.K., Bjerke, J.W., Callaghan, T.V., Huyer-Brugman, F. \& Berg, M.P. (2012) Extreme winter warming events more negatively impact small rather than large soil fauna: shift in community composition explained by traits not taxa. Global Change Biology, 18, 1152-1162.

Bonkowski, M. \& Roy, J. (2012) Decomposer community complexity affects plant competition in a model early successional grassland community. Soil Biology and Biochemistry, 46, 41-48.

Chahartaghi, M., Langel, R., Scheu, S. \& Ruess, L. (2005) Feeding guilds in Collembola based on nitrogen stable isotope ratios. Soil Biology and Biochemistry, 37, 1718-1725.

Chauvat, M., Perez, G. \& Ponge, J.-F. (2014) Foraging patterns of soil springtails are impacted by food resources. Applied Soil Ecology, 82, 72-77.

Chauvat, M., Titsch, D., Zaytsev, A.S. \& Wolters, V. (2011) Changes in soil faunal assemblages during conversion from pure to mixed forest stands. Forest Ecology and Management, 262, 317-324.

Coleman, D.C., Crossley, D.A. \& Hendrix, P.F. (2004) Fundamentals of Soil Ecology. Elsevier Academic Press, Cambridge, MA, USA.

Coleman, D.C. \& Whitman, W.B. (2005) Linking species richness, biodiversity and ecosystem function in soil systems. Pedobiologia, 49, 479-497.

Connell, J.H. (1978) Diversity in Tropical Rain Forests and Coral Reefs High diversity of trees and corals is maintained. Science, 199, 1302-1310.

Cornelissen, J.H.C., Lavorel, S., Garnier, E., Díaz, S., Buchmann, N., Gurvich, D.E. et al. (2003) A handbook of protocols for standardised and easy measurement of plant functional traits worldwide. Australian Journal of Botany, 51, 335-380.

Cornwell, W.K. \& Ackerly, D.D. (2009) Community assembly and shifts in plant trait distributions across an environmental gradient in coastal California. Ecological Monographs, 79, 109-126.

Cornwell, W.K., Schwilk, D.W. \& Ackerly, D.D. (2006) A trait-based test for habitat filtering: convex hull volume. Ecology, 87, 1465-1471.

Cornwell, W.K., Cornelissen, J.H.C., Amatangelo, K., Dorrepaal, E., Eviner, V.T., Godoy, O. et al. (2008) Plant species traits are the predominant control on litter decomposition rates within biomes worldwide. Ecology Letters, 11, 1065-1071.

Craine, J., Froehle, J. \& Tilman, D. (2001) The relationships among root and leaf traits of 76 grassland species and relative abundance along fertility and disturbance gradients. Oikos, 2, 274-285.

De Deyn, G.B., Raaijmakers, C.E., Zoomer, H.R., Berg, M.P., deRuiter, P.C., Verhoef, H.A. et al. (2003) Soil invertebrate fauna enhances grassland succession and diversity. Nature, 422, 711-713.

Debastiani, V.J. \& Pillar, V.D. (2012) SYNCSA-R tool for analysis of metacommunities based on functional traits and phylogeny of the community components. Bioinformatics, 28, 2067-2068.

Didden, W.A.M. (1987) Reactions of Onychiurus fimatus (Collembola) to loose and compact soil. Methods and first results. Pedobiologia, 30, 93-100.
Eisenhauer, N., Sabais, A.C.W. \& Scheu, S. (2011) Collembola species composition and diversity effects on ecosystem functioning vary with plant functional group identity. Soil Biology and Biochemistry, 43, 1697-1704.

Ellenberg, H., Weber, H.E., Dull, R., Wirth, V., Werner, W. \& Paulissen, D. (1991) Zeigerwerte von Pflanzen in Mitteleuropa. Scripta Geobotanica, 18, 1-248.

Endlweber, K. \& Scheu, S. (2006) Effects of Collembola on root properties of two competing ruderal plant species. Soil Biology and Biochemistry, 38, 2025-2031.

Filser, J. (2002) The role of Collembola in carbon and nitrogen cycling in soil: Proceedings of the Xth international Colloquium on Apterygota, České Budejovice 2000: Apterygota at the Beginning of the Third Millennium. Pedobiologia, 46, 234-245.

Forey, E., Coulibaly, S.F.M. \& Chauvat, M. (2015) Flowering phenology of a herbaceous species (Poа апnиa) is regulated by soil Collembola. Soil Biology and Biochemistry, 90, 30-33.

Fortunel, C., Garnier, E., Joffre, R. \& Kazakou, E. (2009) Leaf traits capture the effects of land use changes and climate on litter decomposability of grasslands across Europe. Ecology, 90, 598-611.

Fournier, B., Samaritani, E., Shrestha, J., Mitchell, E.A.D. \& Le Bayon, R.C. (2012) Patterns of earthworm communities and species traits in relation to the perturbation gradient of a restored floodplain. Applied Soil Ecology, 59, 87-95.

Fournier, B., Gillet, F., Le Bayon, R.-C., Mitchell, E.A.D. \& Moretti, M. (2015) Functional responses of multi-taxa communities to disturbance and stress gradients in a restored floodplain. Journal of Applied Ecology, 52, 1364-1373.

Fox, J.W. (2013) The intermediate disturbance hypothesis should be abandoned. Trends in Ecology and Evolution, 28, 86-92.

Frenette-Dussault, C., Shipley, B. \& Hingrat, Y. (2013) Linking plant and insect traits to understand multitrophic community structure in arid steppes. Functional Ecology, 27, 786-792.

Gerisch, M., Agostinelli, V., Henle, K. \& Dziock, F. (2012) More species, but all do the same: contrasting effects of flood disturbance on ground beetle functional and species diversity. Oikos, 121, 508-515.

Gisin, H. (1943) Ökologie Und Lebensgemeinschaften Der Collembolen Im Schweizerischen Exkursionsgebiet Basels: Inauguraldissertation... Vorgelegt Der Philosophisch-Naturwissenschaftlichen Fakultät Der Universität Basel von Hermann Gisin... A. Kundig.

Gorman, C.E., Read, Q.D., Van Nuland, M.E., Bryant, J.A.M., Welch, J.N., Altobelli, J.T. et al. (2013) Species identity influences belowground arthropod assemblages via functional traits. AoB Plants, 5, 1-7.

Grime, J.P. (2001) Plant Strategies, Vegetation Processes and Ecosystem Properties, 2nd edn. John Wiley \& Sons, Chichester, UK.

Guézennec, L., Lafite, R., Dupont, J.-P., Meyer, R. \& Boust, D. (1999) Hydrodynamics of suspended particulate matter in the tidal freshwater zone of a macrotidal estuary (the Seine Estuary, France). Estuaries, 22, 717-727.

Hasegawa, M. (2002) The response of collembolan community to the amount and composition of organic matter of a forest floor. Pedobiologia, 46, 353-364.

Hedde, M., Van Oort, F. \& Lamy, I. (2012) Functional traits of soil invertebrates as indicators for exposure to soil disturbance. Environmental Pollution, 164, 59-65.

Heemsbergen, D.A., Berg, M.P., Loreau, M., vanHal, J.R., Faber, J.H. \& Verhoef, H.A. (2004) Biodiversity effects on soil processes explained by interspecific functional dissimilarity. Science (New York, N.Y.), 306, 1019-1020

Hooper, D.U., Bignell, D.E., Brown, V.K., Brussard, L., Mark Dangerfield, J., Wall, D.H. et al. (2000) Interactions between aboveground and belowground biodiversity in terrestrial ecosystems: patterns, mechanisms, and feedbacks. BioScience, 50, 1049-1061.

Hopkin, S.P. (1997) Biology of the Springtails: (Insecta: Collembola). Oxford University Press, Oxford, UK.

Hopkin, S.P. (2007) A Key to the Collembola (Springtails) of Britain and Ireland. FSC Publications, Telford, UK.

Joosse, E.N.G. (1981) Ecological strategies and population regulation of Collembola in heterogeneous environments. Pedobiologia, 4, 213222.

Kardol, P., Reynolds, W.N., Norby, R.J. \& Classen, A.T. (2011) Climate change effects on soil microarthropod abundance and community structure. Applied Soil Ecology, 47, 37-44.

Kattge, J., Diaz, S., Lavorel, S., Prentice, I.C., Leadley, P., Bönisch, G. et al. (2011) TRY-a global database of plant traits. Global Change Biology, 17, 2905-2935. 
Kembel, S.W., Cowan, P.D., Helmus, M.R., Cornwell, W.K., Morlon, H. Ackerly, D.D. et al. (2010) Picante: R tools for integrating phylogenies and ecology. Bioinformatics, 26, 1463-1464.

Laliberté, E., Legendre, P. \& Shipley, B. (2014) FD: measuring functiona diversity from multiple traits, and other tools for functional ecology. R package version $1.0-12$

Lambeets, K., Vandegehuchte, M.L., Maelfait, J.-P. \& Bonte, D. (2009) Understanding the impact of flooding on trait-displacements and shifts in assemblage structure of predatory arthropods on river banks. Journal of Animal Ecology, 77, 1162-1174.

Lavorel, S., Díaz, S., Cornelissen, J., Garnier, E., Harrison, S.P., McIntyre, S. et al. (2007) Plant functional types: are we getting any closer to the Holy Grail? Terrestrial Ecosystems in a Changing World, pp. 149-164. Springer Science \& Business Media, Heidelberg, Germany

Lessel, T., Marx, M.T. \& Eisenbeis, G. (2011) Effects of ecological flooding on the temporal and spatial dynamics of carabid beetles (Coleoptera, Carabidae) and springtails (Collembola) in a polder habitat. ZooKeys, 100, 421-446.

Lite, S.J., Bagstad, K.J. \& Stromberg, J.C. (2005) Riparian plant species richness along lateral and longitudinal gradients of water stress and flood disturbance, San Pedro River, Arizona, USA. Journal of Arid Environments, 63, 785-813.

MacArthur, R. \& Levins, R. (1967) The limiting similarity, convergence, and divergence of coexisting species. American Naturalist, 101, 377-385.

Makkonen, M., Berg, M.P., van Hal, J.R., Callaghan, T.V., Press, M.C. \& Aerts, R. (2011) Traits explain the responses of a sub-arctic Collembola community to climate manipulation. Soil Biology and Biochemistry, $\mathbf{4 3}$ 377-384

Marx, M.T., Wild, A.-K., Knollmann, U., Kamp, G., Wegener, G. \& Eisenbeis, G. (2009) Responses and adaptations of collembolan communities (Hexapoda: Collembola) to flooding and hypoxic conditions. Pesquisa Agropecuária Brasileira, 44, 1002-1010.

Mason, N.W.H., Richardson, S.J., Peltzer, D.A., de Bello, F., Wardle, D.A. \& Allen, R.B. (2012) Changes in coexistence mechanisms along a long-term soil chronosequence revealed by functional trait diversity. Journal of Ecology, 100, 678-689.

McGill, B.J., Enquist, B.J., Weiher, E. \& Westoby, M. (2006) Rebuilding community ecology from functional traits. Trends in Ecology \& Evolution, 21, 178-185.

Messier, J., McGill, B.J. \& Lechowicz, M.J. (2010) How do traits vary across ecological scales? A case for trait-based ecology. Ecology Letters, 13, 838-848.

Moretti, M. \& Legg, C. (2009) Combining plant and animal traits to assess community functional responses to disturbance. Ecography, 32, 299-309.

Pakeman, R.J. \& Stockan, J.A. (2014) Drivers of functional diversity in carabid beetles: environmental, plant functional traits or plant functional diversity? Ecology, 95, 1213-1224.

Perez, G., Decaëns, T., Dujardin, G., Akpa-Vinceslas, M., Langlois, E. \& Chauvat, M. (2013) Response of collembolan assemblages to plant species successional gradient. Pedobiologia, 56, 169-177.

Pérez-Harguindeguy, N., Díaz, S., Garnier, E., Lavorel, S., Poorter, H., Jaureguiberry, P. et al. (2013) New handbook for standardised measurement of plant functional traits worldwide. Australian Journal of Botany, 61, 167-234.

Petersen, H. (2002) General aspects of collembolan ecology at the turn of the millennium: Proceedings of the Xth international Colloquium on Apterygota, České Budějovice 2000: Apterygota at the Beginning of the Third Millennium. Pedobiologia, 46, 246-260

Pillar, V.D. \& Sosinski, E.E. Jr (2003) An improved method for searching plant functional types by numerical analysis. Journal of Vegetation Science, 14, 323-332.

Pillar, V.D., Duarte, L.D.S., Sosinski, E.E. \& Joner, F. (2009) Discriminating trait-convergence and trait-divergence assembly patterns in ecological community gradients. Journal of Vegetation Science, 20, 334-348.

Podgaiski, L.R., Joner, F., Lavorel, S., Moretti, M., Ibanez, S., Mendonça, M.D.S. et al. (2013) Spider trait assembly patterns and resilience under fire-induced vegetation change in South Brazilian Grasslands. PLoS One, 8, e60207.

Ponge, J.F. (1993) Biocenoses of Collembola in Atlantic temperate grasswoodland ecosystems. Pedobiologia, 37, 223-244.

R Development Core Team. (2015) R: A language and environment for statistical computing. R Foundation for Statistical Computing, Vienna, Austria.

Ribera, I., Dolédec, S., Downie, I.S., Foster, G.N. \& Apr, N. (2001) Effect of land disturbance and stress on species traits of ground beetle assemblages. Ecology, 82, 1112-1129.
Russell, D.J. \& Griegel, A. (2006) Influence of variable inundation regimes on soil collembola. Pedobiologia, 50, 165-175.

Ryan, M. (2002) Insect chemoreception: fundamental and applied. The Chemoreceptive Organs: Structural Aspects (ed. M.F. Ryan), pp. 113139. Springer Netherlands, Dordrecht, the Netherlands.

Salamon, J.-A., Schaefer, M., Alphei, J., Schmid, B. \& Scheu, S. (2004) Effects of plant species diversity, identity and architectural density on the density of Collembola in an experimental grassland. Oikos, 106, 51-60.

Salmon, S. \& Ponge, J.F. (2012) Species traits and habitats in springtail communities: a regional scale study. Pedobiologia, 55, 295-301.

Salmon, S., Ponge, J.F., Gachet, S., Deharveng, L., Lefebvre, N. \& Delabrosse, F. (2014) Linking species, traits and habitat characteristics of Collembola at European scale. Soil Biology and Biochemistry, 75, 73-85.

Scheu, S. (2001) Plants and generalist predators as links between the belowground and above-ground system. Basic and Applied Ecology, 13, 3-13.

Scheu, S., Theenhaus, A. \& Jones, T.H. (1999) Links between the detritivore and the herbivore system: effects of earthworms and Collembola on plant growth and aphid development. Oecologia, 119, 541-551.

Schlesinger, W.H. \& Andrews, J.A. (2000) Soil respiration and the global carbon cycle. Biogeochemistry, 48, 7-20.

Sterzyńska, M., Shrubovych, J. \& Kaprus, I. (2014) Effect of hydrologic regime and forest age on Collembola in riparian forests. Applied Soil Ecology, 75, 199-209.

Stevens, R.D., Cox, S.B., Strauss, R.E. \& Willig, M.R. (2003) Patterns of functional diversity across an extensive environmental gradient: vertebrate consumers, hidden treatments and latitudinal trends. Ecology Letters, 6, 1099-1108.

Vandewalle, M., deBello, F., Berg, M.P., Bolger, T., Dolédec, S., Dubs, F. et al. (2010) Functional traits as indicators of biodiversity response to land use changes across ecosystems and organisms. Biodiversity and Conservation, 19, 2921-2947.

Villéger, S., Mason, N.W.H. \& Mouillot, D. (2008) New multidimensional functional diversity indices for a multifaceted framework in functional ecology. Ecology, 89, 2290-2301.

Violle, C., Bonis, A., Plantegenest, M., Cudennec, C., Damgaard, C., Marion, B. et al. (2011) Plant functional traits capture species richness variations along a flooding gradient. Oikos, 120, 389-398.

Violle, C., Enquist, B.J., McGill, B.J., Jiang, L., Albert, C.H., Hulshof, C. et al. (2012) The return of the variance: intraspecific variability in community ecology. Trends in Ecology and Evolution, 27, 244-252.

Voesenek, L.A C.J., Colmer, T.D., Pierik, R., Millenaar, F.F. \& Peeters, A.J.M. (2006) How plants cope with complete submergence. New Phytologist, 170, 213-226.

Wardle, D., Bardgett, R. \& Klironomos, J. (2004) Ecological linkages between aboveground and belowground biota. Science, 304, 1629-1633.

Westoby, M., Falster, D.S., Moles, A.T., Vesk, P.A. \& Wright, I.J. (2002) Plant ecological strategies: some leading dimensions of variation between species. Annual Review of Ecology and Systematics, 33, 125-159.

Widenfalk, L.A., Bengtsson, J., Berggren, Å., Zwiggelaar, K., Spijkman, E., Huyer-Brugman, F. et al. (2015) Spatially structured environmental filtering of collembolan traits in late successional salt marsh vegetation. Oecologia, 179, 537-549.

Wilson, J. (2007) Trait-divergence assembly rules have been demonstrated: Limiting similarity lives! A reply to Grime. Journal of Vegetation Science, 18, 451-452.

Received 5 October 2015; accepted 1 July 2016

Handling Editor: Hefin Jones

\section{Supporting Information}

Additional Supporting Information may be found online in the supporting information tab for this article:

Appendix S1. References to the individual data sets contributors from the TRY data base.

Appendix S2. Details for modelization of plant and Collembola diversity in response to flooding.

Appendix S3. Details on the TCAP/TDAP methodology used in the paper.

Appendix S4. Community-Weighted Means (CWM) of several plant traits along the flooding gradient. 